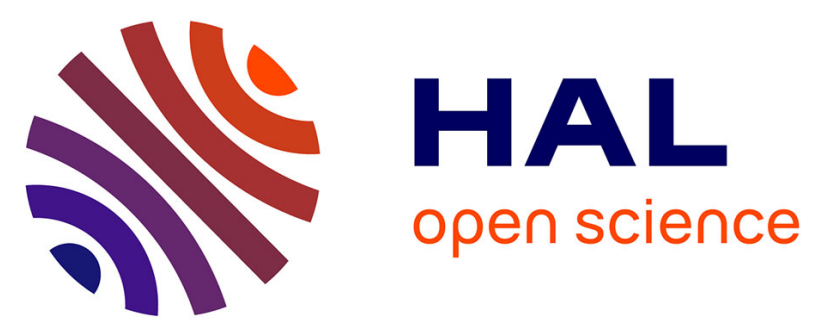

\title{
Comparison of two means of attachment of an organometallic acid on gold surfaces by combining X-ray photoelectron spectroscopy and IR reflection spectroscopy
}

Chloé Chavigny, Franck Le Bideau, Claire-Marie Pradier, Serge Palacin, Pierre Brossier, Gérard Jaouen

\section{To cite this version:}

Chloé Chavigny, Franck Le Bideau, Claire-Marie Pradier, Serge Palacin, Pierre Brossier, et al.. Comparison of two means of attachment of an organometallic acid on gold surfaces by combining X-ray photoelectron spectroscopy and IR reflection spectroscopy. Chemical Communications, 1998, 16, pp.1727-1728. 10.1039/A802551G . cea-01057052

\section{HAL Id: cea-01057052 \\ https://hal-cea.archives-ouvertes.fr/cea-01057052}

Submitted on 26 Aug 2014

HAL is a multi-disciplinary open access archive for the deposit and dissemination of scientific research documents, whether they are published or not. The documents may come from teaching and research institutions in France or abroad, or from public or private research centers.
L'archive ouverte pluridisciplinaire HAL, est destinée au dépôt et à la diffusion de documents scientifiques de niveau recherche, publiés ou non, émanant des établissements d'enseignement et de recherche français ou étrangers, des laboratoires publics ou privés. 


\title{
Comparison of two means of attachment of an organometallic acid on gold surfaces by combining $\mathrm{X}$-ray photoelectron spectroscopy and IR reflection spectroscopy
}

\author{
Caroline Chavigny, ${ }^{a}$ Franck Le Bideau, ${ }^{a}$ Claire-Marie Pradier, ${ }^{a}$ Serge Palacin, ${ }^{b}$ Pierre Brossier ${ }^{c}$ and Gérard \\ Jaouen ${ }^{* * \dagger}$ \\ a Ecole Nationale Supérieure de Chimie de Paris, 11 rue Pierre et Marie Curie, 75231 Paris Cedex 05, France \\ ${ }^{b}$ Service de Chimie Moléculaire, CEA/Saclay, 91191 Gif sur Yvette, France \\ c Faculté de Pharmacie de l'Université de Bourgogne, 7, Boulevard Jeanne d'Arc, 21033 Dijon, France
}

Two methods of immobilization of the butyric 4-oxocyclopentadienylmanganese tricarbonyl acid I on gold surface are presented: either through the assembly of a disulfide derived from the acid, or by coupling on a cystamine monolayer; the efficiency of these two ways are evaluated by IR reflection spectroscopy and X-ray photoelectron spectroscopy.

The research of new immunoassay methods avoiding the drawbacks of radioactive tracers appears to be a main line in analysis. ${ }^{1}$ We recently demonstrated the possibility to assay drugs, hormones and pesticides by FTIR spectroscopy using organometallic markers. ${ }^{2}$ For that purpose, we took advantage of the specific and intense $v_{\mathrm{CO}}$ stretching vibration of the metal carbonyl $\left[\mathrm{M}_{y}(\mathrm{CO})_{x}\right]$ within $1900-2150 \mathrm{~cm}^{-1}$. Moreover, this method might be one of the rare realistic approaches to multiimmunoassays thanks to the characteristic positions of the metal carbonyl groups signals. ${ }^{1}$

So far the analysis was performed in solution and required a separation of the free tracer and the antibody-linked tracer. This step was time demanding and turned out to be incompatible with a large scale analytical development. In order to perform this analysis in the solid state, we investigated the immobilization and detectability of organometallic-marked biological molecules. Biological material can be immobilized on a surface as a host in polymer thin films, ${ }^{3}$ as a host or an adduct within Langmuir-Blodgett films ${ }^{4}$ or can be grafted via covalent bonds on a self-assembled monolayer (SAM). ${ }^{5}$ We selected the third method because it provides bioactive films with high accessibility for external molecules.

Self-assembled monolayers on gold surfaces are generally prepared from dilute solutions of thiols (or disulfides). Biomolecules can be attached to the surface via the terminal functional groups of the assembled thiolate. Before working on the biological matrix, we studied the detectability of manganese tricarbonyl complexes immobilized on the gold surface by IR reflection spectroscopy (IRS). The present study is necessary because the immobilization of metal carbonyl complexes on gold surfaces is a quite new research field. $6,7 \mathrm{We}$ report here a comparison between two means of attachment of an organometallic acid, the butyric 4-oxocyclopentadienylmanganese tricarbonyl I I, on gold surface. Acid I can be prepared following a known synthesis using cymantrene. ${ }^{8}$ The attachment of the acid was carried out either in one step with a disulfide derived from the acid I (method A) or in two steps via the linkage of I with a chemically reactive SAM (method B). We used two different and complementary surface spectroscopies to evaluate the efficiency of these two strategies: IR reflection spectroscopy to detect the carbonyl vibrations, and photoelectron X-ray spectroscopy to compare the molecular densities through the S/Au peak area ratio.

To achieve method A, the organometallic acid I was transformed into a surface-active molecule. Esterification of $\mathbf{I}$ was performed with $N, N, N^{\prime}, N^{\prime}$-tetramethyl(succinimido)uron- ium tetrafluoroborate (TSU) and diisopropyl amine in anhydrous $\mathrm{DMF}^{9}$ to give the $N$-hydroxysuccinimide ester II. The disulfide III was then formed by overnight reaction of the ester with cystamine in anhydrous DMF in the presence of triethylamine [Scheme 1(a)].

SAMs of the disulfide III were prepared on gold substrates ${ }^{10}$ previously cleaned with UV/ozone treatment. The substrates were then placed in a dilute solution $(1.5 \mathrm{~mm})$ of III in distilled THF for $20 \mathrm{~h}$.

The IR reflection spectra of the monolayer ${ }^{11}$ obtained via method A is shown in Fig. 1(a). The bands at 2041 and 1968 $\mathrm{cm}^{-1}$ are characteristic of the metal carbonyl vibrations, and did not change with reaction time, which indicates that an equilibrium state was reached. A shift to higher frequencies is observed compared to the IR spectrum of the pure compound (the E mode vibration of the pure compound is observed at 1940 $\mathrm{cm}^{-1}$ ). We believe that this shift is due to hydrogen bonds ${ }^{12}$ occurring in the pure compound which lower the frequencies. On the gold surface, such interactions are prevented. The observed frequencies are the same as those in $\pi$-acetylcyclopentadienyl manganese tricarbonyl (2040 and $1965 \mathrm{~cm}^{-1}$ in $\mathrm{KBr}$ disc), ${ }^{13}$ which has a similar electron withdrawing substituent on the ring and no possible hydrogen bonds.

In method B, we first prepared the monolayer of cystamine by soaking the gold substrates for $3 \mathrm{~h}$ in a solution of cystamine dihydrochloride $(0.05 \mathrm{M})$ in water. Upon removal from the solution, the substrates were rinsed with $20 \mathrm{ml}$ of water, $5 \mathrm{ml}$ of absolute ethanol and then were dried under nitrogen.

The covalent link of the acid I was constructed by first activating the acid into the ester II. The cystamine monolayer was then immersed for $20 \mathrm{~h}$ in the solution, and some diisopropylethylamine added. ${ }^{14}$ The protocol is illustrated in Scheme 1(b). A 'test slide' was prepared at the same time following the same procedure but without TSU, in order to check the efficiency of the activation. Both were rinsed by two 2 min immersions in DMF, then one in absolute ethanol, dried and analyzed by IRS. The IR reflection spectra obtained via
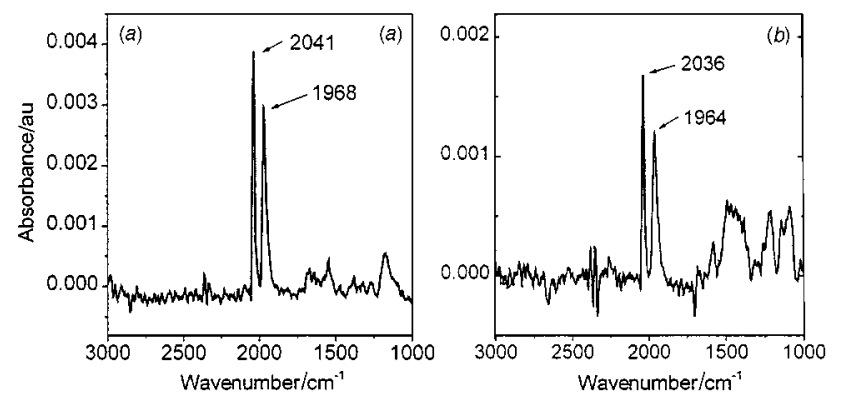

Fig. 1 IR reflection spectra of $(a)$ the disulfide III monolayer and $(b)$ the result of coupling on a cystamine monolayer 


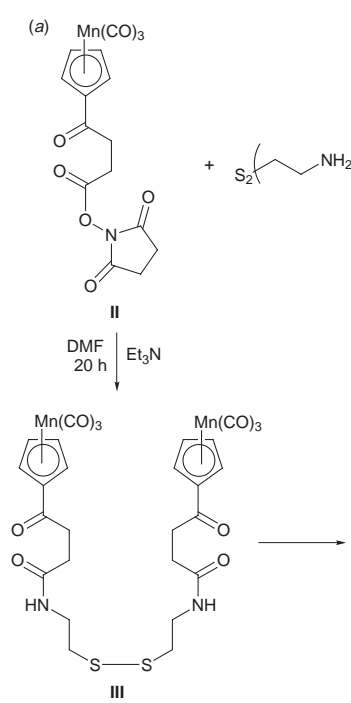

III
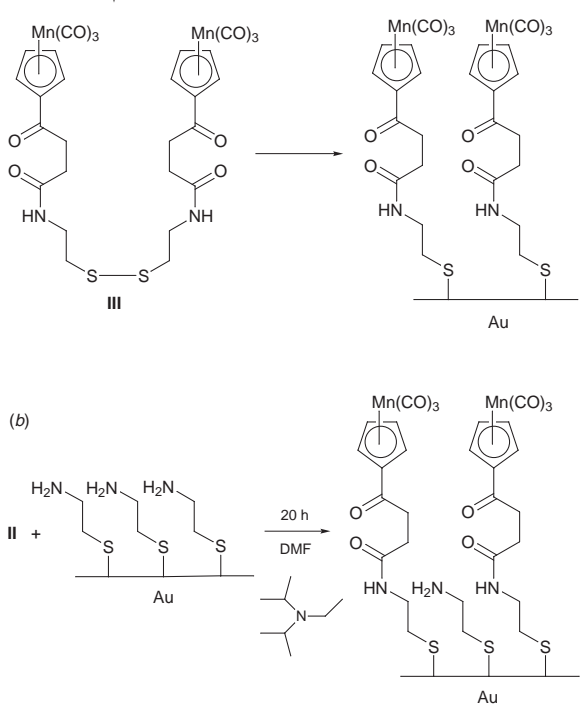

Scheme 1 Methods of attachment of acid I onto a gold surface; $(a)$ method $\mathrm{A}$ and $(b)$ method $\mathrm{B}$

method B is shown in Fig. 1(b). The covalent coupling of the acid on the surface was proved by the absence of carbonyl vibration bands on the 'test gold slide'.

We now want to compare the two methods of attachment of the organometallic acid I on gold. The measurements of the areas of the IR bands at respectively 2041 and $2036 \mathrm{~cm}^{-1}$ shows that the carbonyl $\mathrm{E}$ vibration band is $48 \%$ lower when the attachment was performed via method B than via method A. Therefore, a discussion of this result requires an evaluation of the density of the sulfur sites within the monolayer built from the disulfide III and from cystamine.

We performed XPS analyses at normal incidence on both surfaces and calculated the S/Au ratio. At normal incidence, the thickness of the SAM has a negligible influence on the intensity of the XPS signal. ${ }^{15}$ The S 2 p photoelectron spectra of the layers of cystamine and disulfide III exhibit a peak at $162 \mathrm{eV}$ which is in good agreement with the thiolate moiety on gold. ${ }^{16}$ The ratios $I_{\mathrm{S}} / I_{\mathrm{Au}}$ are 0.0084 for the disulfide III monolayer, and 0.0094 for the cystamine one, which indicates that the molecular density for the cystamine monolayer on the gold surface is a few percent higher than for III (considering the experimental error in XPS). We assume that this is not a significant reason for the observed variation in the infrared intensities.

Therefore, the difference in the areas of the carbonyl vibration bands between SAMs prepared via method A and B is mainly ascribed to the yield of attachment in the adsorbed phase. Note that the different orientations of the metal carbonyl groups may also account for variations of the IR intensities as the reflection mode is only sensitive to the contribution of the dipole moments normal to the surface. However, considering the roughness of the surface at the molecular scale, and the likely amorphous character of these monolayers constituted by molecules having bulky terminal groups, we assume that the metal carbonyl moieties of $C_{3 \mathrm{v}}$ symmetry are randomly oriented. The observed IR signal is consequently unaffected by a preferential orientation of the molecules, but essentially determined by the number of attached metal carbonyl moieties. Therefore, the yield of attachment is the main factor for the differences in the IRS spectra. We found that the attachment via method B was ca. $45 \%$ of the attachment via method A (average of three experimental values taking into account the slight difference in surface densities shown by XPS).

This value can be compared to the $40 \%$ of activated $\mathrm{CO}_{2} \mathrm{H}$ obtained after one cycle of activation of the 11-mercaptoundecanoic acid groups by $N$-hydroxysulfosuccinimide (NHSS) with EDC. ${ }^{17}$ The limited yield of $40-45 \%$ in both cases underlines the importance of the steric effects.

An organometallic acid was covalently attached to a cystamine monolayer on gold. The amount of attachment was evaluated by combining two surface techniques, XPS and IRS, and comparing the signals of the monolayer obtained after coupling into the adsorbed phase with those from the corresponding disulfide layer.

This work allows us to envisage an immunoassay using organometallic markers in the solid phase.

We gratefully acknowledge research grants from CNRS and Region Bourgogne (France) and D.R.E.T., Délégation Générale pour l'Armement (DGA).

\section{Notes and References}

$\dagger$ E-mail: jaouen@extjussieu.fr

1 A. Varenne, A. Vessières, M. Salmain, S. Durand, P. Brossier and G. Jaouen, Anal. Biochem., 1996, 242, 172 and references therein.

2 G. Jaouen, A. Vessières and I. S. Butler, Acc. Chem. Res., 1993, 26, 316.

3 G. Bidan, Sensing effects in electroconducting conjugated polymers in Polymer Films in Sensor Applications, Technomic Publ. Co. Inc., ed. G. Harsani, Basel, 1995.

4 W. M. Reichert, C. J. Bruckner and J. Joseph, Thin Solid Films, 1987, 152, 345 .

5 Th. Wink, S. J. van Zuilen, A. Bult and W. P. van Bennekom, Analyst, 1997, 122, 43R.

6 D. Kang and M. S. Wrighton, Langmuir, 1991, 7, 2169.

7 T. T. Ehler, N. Malmberg, K. Carron, B. P. Sullivan and L. J. Noe, J. Phys. Chem. B., 1997, 101, 3174.

8 R. Dabard and M. Le Plouzennec, Bull. Soc. Chim. Fr., 1972, 3, 3594.

9 W. Bannwarth, D. Schmidt, R. L. Stallard, C. Hornung, R. Knorr and F. Müller, Helv. Chim. Acta, 1988, 71, 2085.

10 The gold substrates $\left(1 \mathrm{~cm}^{2}\right)$ were purchased from EMFCorp. (Evaporated Metal Film Corporation). They consist of glass substrates covered with $50 \AA$ of Ti and $1000 \AA$ of gold.

11 We use the term 'self-assembled monolayer' for this organic film cautiously, as we did not characterize the extent of order of the layer.

12 B. V. Lokshin, S. G. Kazaryan and A. G. Ginzburg, Bull. Acad. Sci. USSR, Div. Chem. Sci., 1988, 257.

13 F. A. Cotton and J. R. Leto, Chem. Ind., 1958, 1368.

14 The addition of an organic base was necessary in order to deprotonate the cystamine dihydrochloride. Only the $\mathrm{NH}_{2}$ functionalities actually react with the activated ester.

15 H. A. Biebuyck, C. D. Bain and G. M. Whitesides, Langmuir, 1994, 10, 1825.

16 C. D. Bain, H. A. Biebuyck and G. M. Whitesides, Langmuir, 1989, 5, 723.

17 B. L. Frey and R. M. Corn, Anal. Chem., 1996, 68, 3187.

Received in Cambridge, UK, 3rd April 1998; 8/02551G 